\title{
Aplicação do modelo multidimensional-reflexivo para análise de uma entidade pública municipal: Autarquia de Esporte e Lazer do Recife (PE)
}

\author{
Brunna Carvalho Almeida ${ }^{1}$, Sílvio Luiz de Paula ${ }^{1}$
}

\author{
${ }^{1}$ Faculdade Boa Viagem. \\ Correspondência: E-mail: silvio_paula@hotmail.com \\ Rua Henrique Rabêlo, 87 \\ Ibura - Recife - PE - Brasil \\ CEP 51320-390
}

Resumo Este artigo tem como objetivo proceder a análise organizacional-administrativa de uma entidade pública que não tem como fim a maximização de lucro. A organização estudada tem por missão de desenvolver o esporte e lazer popular, no município do Recife. No decorrer deste trabalho serão apresentadas as características estruturais e dos agentes do Ginásio de Esportes Geraldo Magalhães com base no modelo multidimensional-reflexivo, que originalmente foi concebido para analisar entidades privadas. Para tanto, os procedimentos analíticos foram pautados nas técnicas de pesquisa documental e bibliográfica, assim como a abordagem através do "sujeito implicado" e do "artesanato intelectual", em conformidade com um critério da investigação do conteúdo, o que caracteriza essa pesquisa como exploratório-descritiva. O resultado indica a possibilidade da classificação da autarquia pesquisada (tipo real) próxima ao tipo ideal proposta pelo modelo multidimensional reflexivo. Essa classificação representa um construto que possibilita a análise de uma organização pública, neste caso, a Autarquia de Esporte e Lazer do Recife, que apresentou uma significativa aproximação com uma variante do tipo-base equiparativo-adaptador.

Palavras-chave: análise organizacional, cultura organizacional, eficiência organizacional.

Abstract This article has as objective to proceed the organizationadministrative analysis from a public entity that does not have 
as end the maximization of profit. The studied organization has for mission to develop the sport, in Recife. In elapsing of this work the structural characteristics and of the agents of the Sports Gymnasium Geraldo Magalhães will be presented on the basis of the multidimensional reflexive model, that originally it was conceived to analyze private entities. For in such a way, the analytical procedures had been based in the techniques of bibliographical documentary research and, as well as the boarding through the "implied citizen", in compliance with a criterion of the inquiry of the content, what it characterizes this research as exploration-descriptive. The result indicates the possibility of the classification of the autarchy searched (real type) next to the type proposal for the multidimensional reflexive model. This classification represents one tool that makes possible the analysis of a public organization, in this in case that, the Sports and Leisure Autarchy from Recife, that presented a significant approach with a variant of the type-base comparative-adapter.

Keywords: organization analysis, organization culture, organizational efficiency.

Resumen Este artículo analiza la organización administrativa de la entidad pública que no tienen como objetivo la maximización de los beneficios. La organización estudiada tiene como misión desarrollar el deporte y el ocio popular, en el municipio de Recife. En el curso de esta obra se presentará las características estructurales y los agentes del Centro Deportivo Geraldo Magalhães basado en modelo multidimensional reflexivo, que fue diseñado originalmente para analizar las entidades privadas. En ambos casos, los procedimientos analíticos fueron guiados en las técnicas de investigación documental y referencias bibliográficas, así como el enfoque a través del "sujeto" y la "artesanía intelectual", de conformidad con el criterio de la investigación del contenido, que caracteriza a esta investigación como estudio exploratorio-descriptivo. El resultado indica la posibilidad de que la clasificación de la autarquía investigado (tipo real) cerca del tipo ideal propuesta por modelo multidimensional reflexivo. Esta clasificación es un constructo que permite el análisis de una organización pública, en este caso, el municipio de deporte y ocio en Recife, que mostraron una importante aproximación con una variante del tipo de comparable-adaptador.

Palabras-clave: análisis organizacional, cultura organizacional, eficiencia en la organización. 


\section{Introdução}

O modelo de organização multidimensional-reflexiva tem como inspiração o legado de Max Weber e, como objetivo, a possibilidade de analisar a organização contemporânea. A priori, esse modelo enfatizou as organizações empresariais para sua aplicação, no entanto, várias possibilidades de análise vêm surgindo, principalmente para as organizações públicas.

Esta pesquisa tem a intenção de aplicar o modelo de Alves (2003) a uma autarquia de esporte e lazer da cidade do Recife (PE) a fim de identificar, a partir do tipo real, qual o tipo-base apontado pelo autor, e suas possíveis variações se aproximam da organização estudada.

Para atingir tal objetivo, o artigo segue uma linha onde são desenvolvidos em seu referencial teórico os fundamentos do modelo multidimensional-reflexivo (MMR) trazendo a taxonomia das formas de ação social de Weber (1999) e as estruturas de dominação que inspiraram o MMR - e, as características do modelo, que por sua vez, é estabelecido a partir da inter-relação dos componentes, patriarcado, carisma e burocracia e da interação recíproca dos condicionantes do sistemaorganização e indivíduo-agente. Para Alves (2003), uma organização multidimensional reflexiva (OMR) é representada pela configuração organizacional administrativa com características de gestões patriarcal, carismática e burocrática.

Quanto aos procedimentos metodológicos, foi desenvolvida a pesquisa bibliográfica e documental, assim como a abordagem através do "sujeito implicado" - aquele que está diretamente vinculado àquilo que pesquisa, sendo ao mesmo tempo pesquisador e pesquisado, analisador e analisado - e do "artesanato intelectual", que, segundo a abordagem de Mills (1970) salienta a falácia da neutralidade do pesquisador nas ciências sociais compreendendo o ato da pesquisa como atividade artesanal. Para a análise dos dados coletados, foi realizada a análise do conteúdo, segundo Bardin (1977), buscando destacar o relacionamento organização e indivíduo e, discutindo a articulação dessas duas dimensões organizacionais mutuamente influentes.

Após levantamento dos dados, verificou-se a importância de descrever um pouco sobre a política de esporte e lazer no Brasil e no Recife (PE), a fim de situar o leitor sobre a mudança ocorrida nos objetivos da autarquia estudada. Pois, de forma bastante peculiar, a política de esporte e lazer, no país, passou a ter uma atenção sistemática, com desenvolvimento de projetos articulados entre governo federal, estadual e municipal, somente em 2003, com a criação do Ministério do Esporte. Essa ação desencadeou uma série de responsabilidades de órgãos públicos do setor, o que acarretou, em 2005, a reforma administrativa do órgão e a instituição de novas missões e objetivos para a autarquia.

$\mathrm{Na}$ análise dos dados, são tomados como referência os componentes de estrutura e agência, conforme indicação de Alves (2003). No aspecto estrutura, 
são analisadas as dimensões complexidade, formalização e centralização, com base no estudo de Hall (2004). Sobre o componente agência, são destacados os aspectos de mecanismos de controle e cultura organizacional.

Os resultados indicam a possibilidade de uma classificação da autarquia pesquisada com as seguintes características: uma burocracia menos flexível, com patriarcado renovador e uma fraca presença de liderança carismática. Essa classificação do tipo real (autarquia) próxima ao tipo ideal proposta pelo modelo multidimensional reflexivo significa dizer que a Autarquia de Esporte e Lazer do Recife, apresentou uma significativa aproximação com uma variante do tipo-base equiparativo-adaptador.

\section{Referencial teórico}

\section{Fundamentos do modelo multidimensional reflexivo}

A concepção dos ideais-tipos de Weber, que serviram de base para o modelo multidimensional-reflexivo, são conceitos caracterizadores que visam acentuar o caráter singular de um fenômeno particular para sua compreensão. Assim, podemos dizer que suas tipologias possuem uma natureza explicativa de determinada realidade, não se destinando a ser utilizada como um exemplo do desejável, e sim, uma referência teórica para sua análise. A ação humana também estudada por Weber é tomada como ponto de partida para a elaboração do modelo de análise de Alves (2003).

A taxonomia das formas de ação social de Weber refere-se a quatro tipos: ação racional no tocante aos fins, ação racional com relação a um valor, ação afetiva e ação tradicional. E, as estruturas de dominação correspondem a três tipos, não consideradas em sequência evolutiva: dominação patriarcal, dominação carismática e dominação burocrática.

A dominação patriarcal, segundo Weber (1999), é uma estrutura que se baseia em relações de piedade pessoal, autoridade do chefe de comunidade doméstica. Mesmo tendo características divergentes da dominação burocrática, apresenta alguns pontos em comum que são o serviço com finalidade objetiva, a busca pela continuidade de sua existência e a obediência às normas por parte dos submetidos ao poder.

É de conduta fundamentada na tradição, desta forma, podemos dizer que em relação às normas, a dominação patriarcal tem como característica a submissão pessoal ao senhor ou patriarca o que garante a legitimidade do dominador, assim como a inviolabilidade das normas que sempre foram seguidas por determinada sociedade. 
Neste tipo de dominação os funcionários patrimoniais se apresentam pelas características do seu recrutamento dado através de círculos pessoalmente submetidos, pois, desta forma, a obediência será certa e absoluta. O senhor, por sua vez, possui livre arbítrio e relação aos servos exerce o poder, condicionado apenas pela força da tradição e de acordo com a escala de livre arbítrio, podemos dizer que são "conservadores, reformistas e renovadores" (Alves 2003:30).

A dominação carismática, segundo Weber (1999), é confrontada com os outros dois tipos de dominação: a patriarcal/patrimonial e a burocrática. O autor trata o carisma quanto sua natureza e quanto aos efeitos provocados.

O carisma, diferentemente da estrutura burocrática representada pela impessoalidade e da patriarcal que aponta para o caráter cotidiano, apresenta-se pela natureza da transitoriedade. Além disso, a transcendência às questões econômicas do cotidiano mostra como o líder carismático se caracteriza. A pura estrutura carismática não conhece forma de nomeação, demissão, carreira ou promoção. Suas tarefas são consideradas de cunho voluntário, ou melhor, realizadas através de uma missão.

Quanto aos efeitos provocados pelo carisma, o principal deles está no confronto com a monarquia existente apoiada numa perspectiva da graça divina onde o monarca era responsável perante Deus. Outro aspecto divergente das normas da época era em relação às leis jurídicas. Para os carismáticos os conflitos deveriam ser resolvidos através da "revelação dos profetas", tendo o líder o domínio da escolha na resolução de tais conflitos.

Mesmo não expresso numa ordem cronológica, o carisma, aos poucos, vai dando lugar à racionalidade, aos interesses da vida econômica e se, de um lado há transformação do carisma, de outro, existem algumas esferas que protegem o carisma da racionalidade burocrática, esta atitude está expressa na conduta da igreja que submetem seus líderes carismáticos ao celibato e à renúncia aos bens materiais. Este tipo de estratégia é denomina de rotinização do carisma.

Uma grande problemática da dominação carismática está na sucessão do líder e, neste aspecto, a dominação carismática tem um sério problema, como passar para outra pessoa tributos que thes são pessoais e intransferíveis? Uma estratégia desenvolvida a partir da educação direcionada para formação de líderes busca desenvolver algumas habilidades que foram relacionadas, categorizadas e postas como regras mínimas para ser um bom líder. Todavia, a necessidade de rotinização do carisma para legitimar as camadas privilegiadas em suas situações sociais e econômicas acaba por descaracterizar a própria estrutura de dominação carismática.

A dominação burocrática, por sua vez, está pautada na impessoalidade como característica. O funcionamento da administração moderna com todas as suas exigências e peculiaridades são pautados nessa impessoalidade. 
Weber (1999) apontou características desta organização que contribuíram para a sobrevivência deste tipo de dominação que são:

- O princípio das competências fixas, com distribuição fixa das atividades regularmente necessárias;

- Os poderes de mando fixados por regras; e

- A contratação de pessoas em virtude de competências técnicas.

Para garantia da impessoalidade e da obediência às regras e não às pessoas, todos os documentos são escritos e neste ponto há uma diferenciação entre os documentos pessoais e os de trabalho. As atividades oficiais do trabalhador são especializadas, ou seja, é necessário que o indivíduo tenha qualificação naquilo que está se propondo a trabalhar. Além disso, mesmo que haja uma jornada de trabalho com carga horária determinada é exigido do trabalhador maior dedicação do seu tempo e toda gestão dos funcionários se dá através de regras gerais.

Diante dos princípios acima, Weber (1999) materializa o comportamento dos funcionários interna e externamente à organização. O cargo como uma profissão, exige do funcionário a formação prescrita e o caráter de fidelidade que o indivíduo necessita demonstrar quando da sua ocupação. Por outro lado, algumas características dessa dominação burocrática colocam no funcionalismo a possibilidade de dominação tais como a posição pessoal do funcionário que exige aspiração a estima social, a nomeação por instância superior (seja por eleição ou indicação), a garantia jurídica quanto a sua estabilidade, quanto ao recebimento de sua remuneração e a sua possibilidade de percorrer carreira.

O que proporcionou alargamento e consolidação desta forma de dominação está relacionado à superioridade técnica, ao desenvolvimento da economia monetária e o recebimento de salário. Esses pontos foram cruciais para a manutenção dos hábitos gerais da burocracia.

Assim, pode-se caracterizar a burocracia como materializada pela estrutura burocrática, baseada na crença da legalidade e racionalidade, na obediência às normas e aos preceitos jurídicos, na submissão fundamentada nas relações impessoais, no exercício do poder fixado em leis e regulamentos por quem de direito pode exercê-la. 


\section{Características delineadoras do modelo multidimensional- reflexivo (MMR)}

O modelo multidimensional-reflexivo é estabelecido a partir da inter-relação dos componentes, patriarcado, carisma e burocracia. Além de estabelecer diálogo interdisciplinar usando conceitos da sociologia e administração.

A lógica do modelo explicativo de Alves, bem como colocado em sua definição, trata não apenas de uma simples transcrição dos tipos de dominação, em sua forma idealizada, weberiana, mas sobretudo, examina a configuração organizacional-administrativa como sendo dinâmica onde os três elementos de dominação de Weber se influenciam mutuamente $e$ se relacionam em variadas intensidades (Pereira 2008:41).

Na construção do modelo observa-se a interação reciprocamente condicionantes do sistema-organização e indivíduo-agente. Para Alves (2003), uma organização multidimensional reflexiva (OMR) é representada pela configuração organizacional administrativa com características de gestões patriarcais, que numa organização, pode se configurar além dos vínculos parentescos, estreitamento por questões relacionadas à confiança. Ainda como característica do patriarcado está presente a variabilidade podendo ser reformador, renovador e conservador tendo nessas classificações níveis maiores ou menores de livre arbítrio quanto à tomada de decisões.

A gestão carismática, neste caso, está mais ligada ao componente afetividade que fundamenta o carisma numa organização contemporânea, esta afetividade, por vezes garante a coesão interna e sentido de cumprimento de uma missão que é passada aos demais integrantes da organização enquanto que na gestão burocrática a discussão está para o nível de rigidez dessa burocracia tendo como parâmetro o ideal-tipo weberiano.

Esta discussão permeia outro assunto relacionado ao componente subjetivo presente nas tomadas de decisão, os valores e interesses particulares dos agentes responsáveis pela decisão. Desta forma, a racionalidade instrumental, apresenta-se associada a outros aspectos de "irracionalidade", ou melhor, aspectos não lógicos.

Ainda referindo-se à OMR, é possível dizer que não se trata de um modelo com a intencionalidade de refletir integralmente à realidade, pretende muito mais analisar a realidade organizacional levando em conta características das empresas, tais como: natureza das tarefas, tipo de estratégia adotada, tamanho, tecnologia adotada, dentre outros. 
Essas características, contudo, remetem a uma lógica contingencialista da organização. Além dessas, outra característica da OMR é a incorporação de mecanismos de coordenação de caráter normativo e utilitário e a abordagem contextualizada historicamente, ou seja, leva em consideração o passado, representados nos hábitos e costumes consolidados numa organização (empresa com característica patriarcal), o presente, representado pela experiência imediata, fluxo das atividades correntes (caracterizada pela empresa burocrática) e o futuro, característica de organizações com traços carismáticos.

O agente multidimensional reflexivo (AMR), por sua vez, é um construto teórico com a combinação do patriarca, do líder com traço carismático e do burocrático, agindo sobre influência de uma racionalidade instrumental, no entanto, desfrutando de autonomia e liberdade de ação na empresa, pois, para além da racionalidade instituída, suas ações estão calçadas em valores, sentimentos e laços afetivos. Pode-se citar como características do AMR, a possibilidade de propor alternativas às práticas sufocantes da burocracia e a dualidade nas ações, oscilando entre o racional e o intuitivo.

A limitação da sua racionalidade, confrontada com essas subjetividades e valores, muitas vezes, faz com que os agentes não tenham a exata consciência do porquê de determinadas ações. Além desses fatores, entra na cena organizacional o conflito de suas posições individuais, os outros agentes e grupos integrantes da organização e essa correlação de forças influencia de forma bastante incisiva o momento de uma tomada de decisão.

Sobre este aspecto do agente multidimensional reflexivo, Alves (2003) caracteriza-os como conservador, transformador e adaptador. O primeiro, na expectativa de manter o status quo tenta garantir o cumprimento das ordens de acordo com os costumes, o segundo, com intencionalidade proativa, sugere mudanças e inovações, já o terceiro, como um mediador, procura o equilíbrio entre o costume e a mudança, pois, tem a consciência de que elas são importantes, então, procura adotá-las de forma menos conflituosa.

Diante dessas características dos agentes, Alves (2003), propõe uma tipologia (Quadro 1). 
Quadro 1. Tipologia das organizações multidimensionais-reflexivas. Recife, 2003.

\begin{tabular}{l|l}
\hline \multicolumn{1}{c|}{ Tipologia das OMR } & \multicolumn{1}{c}{ Características } \\
\hline Ordenativa-conservadora & $\begin{array}{l}\text { Empresa que apresenta uma burocracia } \\
\text { rígida, um patriarcado conservador e uma } \\
\text { liderança sem a presença de carisma, ou } \\
\text { seja, suas ações são objetivadas. }\end{array}$ \\
\hline Liberativa-transformadora & $\begin{array}{l}\text { Caracterizada por uma burocracia } \\
\text { incipiente, um patriarcado reformista e } \\
\text { liderança com traços carismáticos uma uma } \\
\text { empresa que apresenta a predominância } \\
\text { do agente em detrimento da estrutura } \\
\text { organizacional. }\end{array}$ \\
\hline Equiparativa-adaptadora & $\begin{array}{l}\text { Empresa que traz uma burocracia flexível, } \\
\text { um patriarcado renovador e lideranças } \\
\text { com traços mitigados de carisma }\end{array}$ \\
& $\begin{array}{l}\text { caracterizam-se por apresentarem certo } \\
\text { equilíbrio entre a organização e o } \\
\text { indivíduo. }\end{array}$
\end{tabular}

Fonte: Dados dos autores (2013).

Essas tipologias mostram a importância de se tratar a organização como decorrente de interação entre empresa, ambiente e indivíduo. Esses modelos sugeridos por Alves (2003) não são estanques e podem sofrer variações de acordo com a intensidade da burocracia, do patriarcado e do carisma. Para melhor entendimento, segue as variações do tipo-base constitutivo do modelo (Quadros 2, 3 e 4).

Quadro 2. Variações do tipo-base equiparativa-adaptadora. Recife, 2003.

\begin{tabular}{l|l|l|l}
\hline $\begin{array}{c}\text { OMR do tipo } \\
\text { equiparativa- } \\
\text { adaptadora }\end{array}$ & \multicolumn{1}{|c|}{ Variação I } & \multicolumn{1}{c}{ Variação II } & Variação III \\
\hline $\begin{array}{l}\text { Burocracia } \\
\text { flexível }\end{array}$ & $\begin{array}{l}\text { Burocracia menos } \\
\text { flexível }\end{array}$ & $\begin{array}{l}\text { Burocracia mais } \\
\text { flexível }\end{array}$ & Burocracia flexível \\
\hline $\begin{array}{l}\text { Patriarcado } \\
\text { renovador }\end{array}$ & $\begin{array}{l}\text { Patriarcado } \\
\text { renovador }\end{array}$ & $\begin{array}{l}\text { Fraca presença ou } \\
\text { eventual ausência da } \\
\text { dimensão patriarcal } \\
\text { renovadora }\end{array}$ & $\begin{array}{l}\text { Fraca presença ou } \\
\text { eventual ausência da } \\
\text { dimensão patriarcal } \\
\text { renovadora }\end{array}$ \\
\hline $\begin{array}{l}\text { Liderança com } \\
\text { traços mitigados }\end{array}$ & $\begin{array}{l}\text { Fraca presença ou } \\
\text { eventual ausência da } \\
\text { dimensão liderança } \\
\text { carismática } \\
\text { moderada }\end{array}$ & $\begin{array}{l}\text { Liderança com traços } \\
\text { mitigados }\end{array}$ & $\begin{array}{l}\text { Fraca presença ou } \\
\text { eventual ausência da } \\
\text { dimensão liderança } \\
\text { carismática } \\
\text { moderada }\end{array}$ \\
\hline
\end{tabular}

Fonte: Alves (2003). 
Quadro 3. Variações do tipo-base ordenativo-conservadora. Recife, 2003.

\begin{tabular}{l|l|l}
\hline $\begin{array}{c}\text { OMR do tipo } \\
\text { ordenativo- } \\
\text { conservadora }\end{array}$ & \multicolumn{1}{|c|}{$\begin{array}{c}\text { Subtipo patriarcal } \\
\text { conservadora }\end{array}$} & \multicolumn{1}{c}{ Subtipo burocrática rígida } \\
\hline $\begin{array}{l}\text { Burocracia rígida } \\
\begin{array}{l}\text { Patriarcado } \\
\text { conservadora }\end{array}\end{array}$ & Burocracia incipiente & Burocracia rígida \\
\hline
\end{tabular}

Fonte: Alves (2003).

Quadro 4. Variações do tipo-base liberativa-transformadora. Recife, 2003.

\begin{tabular}{l|l|l}
\hline $\begin{array}{c}\text { OMR do tipo } \\
\text { liberativa- } \\
\text { transformadora }\end{array}$ & Subtipo patriarcal reformista & Subtipo centrado em um líder \\
\hline $\begin{array}{l}\text { Burocracia } \\
\text { incipiente }\end{array}$ & Burocracia incipiente & Burocracia incipiente \\
\hline $\begin{array}{l}\text { Gestão patriarcal } \\
\text { reformista }\end{array}$ & Gestão patriarcal reformista & $\begin{array}{l}\text { Minimização da dimensão } \\
\text { patriarcal reformista }\end{array}$ \\
\hline $\begin{array}{l}\text { Liderança } \\
\text { empresarial com } \\
\text { traços } \\
\text { carismáticos }\end{array}$ & $\begin{array}{l}\text { Minimização da dimensão } \\
\text { liderança empresarial com traços } \\
\text { carismáticos }\end{array}$ & $\begin{array}{l}\text { Liderança com traços } \\
\text { carismáticos }\end{array}$ \\
\hline
\end{tabular}

Fonte: Alves (2003).

\section{Procedimentos analíticos}

Ao tratar do processo de pesquisa em campo Merhy (2007) chama a atenção para aqueles que são "sujeitos implicados", aqueles que estão diretamente vinculados àquilo que pesquisam, sendo ao mesmo tempo pesquisador e pesquisado, analisador e analisado, um sujeito militante que pretende ser epistêmico e que os desenhos de pesquisa consagrados no campo das ciências não dão conta desse tipo de processo. Nesse sentido, Wright Mills salientou a falácia da neutralidade do pesquisador nas ciências sociais compreendendo o ato da pesquisa como atividade artesanal, isto é, um "artesanato intelectual" fundamentalmente reflexivo (Mills 1970).

$\mathrm{Na}$ análise realizada neste trabalho teve-se claro esse dois aspectos do "sujeito implicado" e do "artesanato intelectual" a fim de refletir os aspectos estruturais e de agência, juntamente com as técnicas documentais, bibliográficas e de análise de conteúdo.

A ideia consiste em aplicar a teoria administrativa através do modelo proposto por Alves (2003) para identificar as características estruturais e dos agentes, numa organização em que um dos autores já manteve vínculo empregatício. 
O presente estudo é caracterizado como exploratório-descritivo. Exploratório por ter como finalidade proporcionar maior familiaridade com o objeto e aprimorar ideias sobre a relação agência-estrutura numa visão de continuum, não padronizando um ou outro comportamento organizacional. E descritivo, por procurar explicitar como se manifesta determinado fenômeno organizacional, discorrendo sobre situações e acontecimentos mais significativos.

Uma das técnicas de coleta de dados a se dá por meio de pesquisa documental, realizada em documentos disponíveis: registros, anais, filmes, fotografias e outros (Vergara 2003). Neste tipo de pesquisa, relacionam-se os documentos de primeira mão, ou seja, aqueles que não receberam nenhum tratamento analítico, tais como os documentos conservados em órgãos públicos, e os documentos de segunda mão que de alguma forma já foram analisados: relatórios de pesquisa, relatórios de empresas, tabelas estatísticas e outros (Gil 1991). Para este trabalho foi estudado os documentos, como o Diário Oficial do Município, documentos públicos disponibilizados pela internet e documentos internos de gestão disponibilizados pelo órgão.

A outra técnica utilizada foi a pesquisa bibliográfica, compreendida pelo universo de trabalhos teóricos desenvolvidos no campo da pesquisa, realizado através de estudo sistematizado de materiais disponibilizados em livros, revistas, jornais, dentre outros.

\section{Políticas públicas setoriais de esporte e lazer}

Para compreensão da atuação da Autarquia Municipal de Esporte é necessária contextualização da política setorial de esporte, uma vez que, diferentemente das organizações privadas que têm seus objetivos relacionados aos interesses de mercado, as organizações públicas primam pelo atendimento à população, a partir das missões e valores que determinadas políticas instituem aos seus órgãos executores. Assim, será realizado um breve histórico das políticas de esporte e lazer no Brasil e no município do Recife.

As políticas públicas de esporte e lazer no Brasil têm uma característica singular, pois, até 2003 não vinham sendo tratadas de forma sistemática, como as políticas de saúde e educação, por exemplo. É constatada a fragilidade desta política em nível nacional, principalmente pela falta de uma estrutura consolidada, tendo o Ministério do Esporte criado somente em 2003. No entanto, - Estado vem intervindo nas organizações esportivas desde 1941 a partir da criação da primeira legislação esportiva e do Conselho Nacional do Desporto (CND).

Ainda sobre a política nacional é notável o aproveitamento político das ações esportivas para promoção de governantes e associação da imagem de sucesso esportivo às referidas gestões, tais como Getúlio Vargas na década de 1940, para 
discussões comemorativas do Dia do Trabalho e Médici, que aproveitou o sucesso do Brasil na Copa de 1970, para insuflar o patriotismo e associar a vitória brasileira ao seu governo (Alves e Pieranti 2007).

No Recife, assim como restante do país, atuação do poder público municipal no setor de Esporte e Lazer tem servido, predominantemente, para atender os interesses econômicos, políticos e ideológicos das forças conservadoras e das classes dominantes, seja através de ações clientelistas e eleitoreiras, seja através da promoção de práticas esportivas e de lazer veiculadoras de valores como a seletividade excludente, a competitividade exacerbada, a especialização precoce e a busca da vitória a qualquer custo, tão caros à sustentação ideológica do sistema (Recife 2002).

Desta forma, pode-se dizer que as políticas de esporte e lazer existentes não consideravam a importância destas atividades para o cidadão comum, sendo recursos investidos em atividades de alto rendimento o que privilegiava àqueles dotados de aptidão física acima da média, com possibilidade de ser considerado atleta. Além disso, a distribuição de materiais esportivos, tais como medalhas e troféus, e a concessão de espaços públicos aos interesses privados (especialmente campos de futebol de várzea que tem sido arrendado para líderes comunitários e estes, por sua vez cobravam taxas da comunidade para uso do espaço), têm sido utilizados como moeda de troca no meio político o que garantia a permanência de muitos vereadores no poder.

Com o advento da Constituição de 1988, a primeira a versar sobre o tema em nosso país, como direito social, em seu artigo 217, afirma que "é dever do estado fomentar práticas desportivas formais e não-formais" (Brasil 1988). No entanto, ao lado do princípio emancipador alocado na estrutura jurídica e política, a estrutura econômica - caracterizada pelo capitalismo contemporâneo - trazia sequelas em virtude da excessiva flexibilização do trabalho, mudando e intervindo nos fatores produtivos tais como: representação do capital pela força do mercado financeiro, a precarização das relações de trabalho e das formas de produção, das mudanças nos padrões gerenciais, como o downsizing e a circulação de mercadoria com a intensiva investida dos marqueteiros oferecendo à população a ideologia do descartável (Fonseca 2007).

Essas questões, de certa forma, explicam o impasse do não avanço das leis e direitos instituídos pela constituição, principalmente na área de esporte e lazer, que não tem sido tratada como direito básico dos cidadãos uma vez que, é necessário conviver lado a lado com o sistema econômico que não permite ou, pelo menos, dificulta a ampliação dos direitos sociais.

Também em consequência dessa estrutura econômica e social constituída pelo capitalismo contemporâneo o que se vê é a mercadorização do mundo e com ele das práticas esportivas e do lazer. 
Associado ao avanço da especulação imobiliária o aumento dos investimentos da iniciativa privada no setor é notório, o que pode ser evidenciado na proliferação das academias de ginástica, dos centros esportivos privados, dos parques de diversão fechados, das casas de jogos eletrônicos etc. (Recife 2002:02).

Assim, a maioria da população se vê alijada do acesso ao esporte, e as formas de lazer em geral, pois não há investida do Estado para que seja universalizada esta prática.

De outro lado, com foco diferenciado das políticas públicas - baseada nos direitos sociais instituídos pela Constituição de 1988 - encontram-se várias possibilidades de um espaço aberto à construção de novas perspectivas e participação social. A descentralização de recursos orçamentários e os arranjos político-federativos em âmbito local dão a gestão pública mais transparência e o Estado, com a inclusão de novos atores, passa a lidar com as barganhadas políticas, com as diversas facetas e interesses desse atores na formulação e implementação das políticas públicas para construir algo que atenda aos interesses de uma maioria e possa assim, legitimar uma política social.

A política setorial de esporte e lazer vem sendo concebida pelo poder público a partir de uma visão utilitária e as ações governamentais são justificadas para compensar as mazelas sociais, combater a violência, afastar crianças das ruas, melhorar a saúde da população. Entretanto, esse caráter "assistencial" das ações governamentais acaba dificultando a realização de ações de esporte e lazer como um direito social.

No intuito de reverter esta lógica na produção de políticas públicas, o governo do município do Recife traz em seus documentos como horizonte.

a responsabilidade ética e política de contribuir para a superação tanto das práticas eleitoreiras e clientelistas, quanto da perspectiva utilitaristafuncionalista no que tange as ações no setor de esporte e lazer. A maior tarefa deste governo é promover as condições concretas para a elevação da consciência e do exercício político da população e, contribuir para livrar o esporte e o lazer dos interesses mercantilistas, elevando-o ao patamar de direito social e cultural. (Recife 2002:04).

Tendo como parâmetro a responsabilidade que se propôs o governo municipal em romper com uma prática política, isto inevitavelmente interferiu nos aspectos organizacionais gerando algumas inovações. E, a partir da concepção de inovação no contexto das organizações classificado por Knight (1967), é 
identificada a inovação em quatro tipos, nos quais apontaremos três relevantes a esse estudo:

- Inovação de processo de produção quando novos elementos são introduzidos na execução das tarefas organizacionais;

- Inovação da estrutura organizacional relativa às mudanças nas relações de autoridade, de comunicação; e

- Inovação de pessoas referente a processos de aprendizagem, especificamente treinamento e desenvolvimento, visando à mudança na cultura organizacional.

Isto porque com esta compreensão do cenário nacional da política de esporte e lazer, o governo municipal instituiu algumas inovações referente ao processo de produção, quando implementou novos elementos na execução das tarefas organizacionais, na estrutura organizacional, ao passo que propôs reforma administrativa na autarquia a fim de atender as demandas na nova política de esporte e lazer assim como, na inovação de pessoas, ao instituir novo corpo gestor com capacidade técnica de assumir tal função, como será detalhado adiante.

\section{Autarquia municipal de esporte e lazer}

Criada através da lei 10.275, de 18 de agosto de 1970 e com sua última alteração em 27 de julho de 2005, pela lei 17.108, a autarquia municipal, Ginásio de Esportes Geraldo Magalhães (Geraldão), passa a ter como finalidade a promoção e desenvolvimento de atividades esportivas amadorísticas no município do Recife a fim de atender as mudanças relativas à política de esporte do município.

De acordo com as diretrizes do governo municipal, as quais preveem uma gestão política radicalmente democrática fundamentada na participação popular, inversão de prioridades e elevação da consciência política, o Geraldão adotou como missão o desenvolvimento do esporte e lazer popular.

Tal missão traduz-se na necessidade de aprofundar a superação das práticas elitistas e clientelistas das administrações tradicionais e combater a mercantilização do Esporte e Lazer, promovendo-os como direito social para todos os segmentos da população e priorizando a educação no e para 
o tempo livre em busca de níveis críticos e criativos de participação. (Recife 2005:03).

E para o cumprimento dessa missão são tomadas como linhas de ação do órgão (Recife 2005):

(1) Democratização da gestão no esporte e lazer;

(2) Revitalização, democratização e normatização do uso público dos espaços de esporte e lazer da cidade;

(3) Implementação de projetos de atividades esportivas e de lazer regulares para os vários segmentos da população recifense, abrangendo as crianças, os jovens, os adultos, as mulheres, os idosos e as pessoas com deficiência;

(4) Apoio às iniciativas esportivas e de lazer espontâneas das comunidades, principalmente nas áreas empobrecidas da cidade;

(5) Criação de um quadro docente e funcional para atuação no setor de esporte e lazer e definição de uma política de valorização profissional;

(6) Fortalecimentos do esporte de alto rendimento, através de parcerias com a iniciativa privada;

(7) Desenvolvimento de projetos direcionados aos alunos da rede municipal de ensino, considerando o esporte e a recreação como elementos fundamentais da formação humana.

A configuração administrativo-organizacional que dá suporte às linhas de ação com o objetivo de garantir o acesso ao esporte e lazer nos diversos segmentos sociais, foi aprovada na lei 17.108/05 (Figura 1). 
Figura 1. Organograma da autarquia municipal de esporte e lazer. Recife, 2005.

\section{Ginásio de Esportes Geraldo Magalhães}

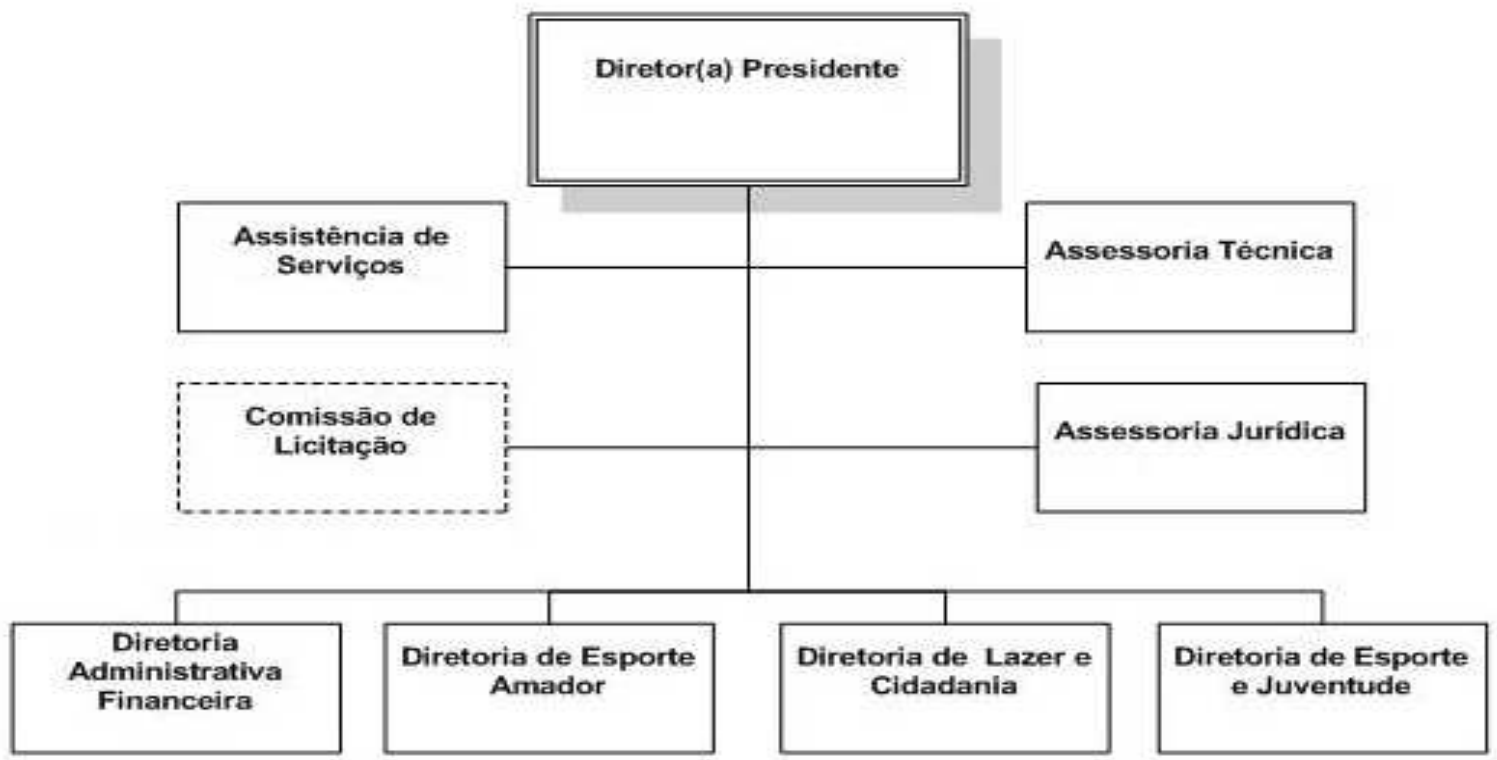

Fonte: Prefeitura Municipal de Recife (2005).

Para garantir as atividades finalísticas, foram criadas quatro diretorias conforme organograma acima (Diretoria Administrativa Financeira, Diretoria de Esporte Amador, Diretoria de Lazer e Cidadania e Diretoria de Esporte e Juventude) todas as que executam projetos têm interface e dialogam entre si, ou seja, na realização de eventos, ou no desenvolvimento de atividades sistemáticas como escolinhas esportivas, as diretorias trabalham correlacionando suas ações e, a diretoria administrativa, atua na garantia das condições materiais para o desenvolvimento dos projetos, atividades e eventos. A presidência, por sua vez, assim como a assessoria jurídica, tratam de assuntos interorganizacionais com outros órgãos e secretarias do município, assim como articulações com outras instituições da iniciativa privada.

Como toda instituição pública a autarquia é regida por leis e normas que vão desde sua constituição ao seu funcionamento, ou seja, a criação e a normatização do órgão deverão ser publicadas na forma da lei. Outras características relevantes para uma organização pública são a centralização e a hierarquização de sua estrutura. No entanto, como poderá ser observado, mais adiante, esta centralização e hierarquização, em parte, não condiz com a realidade do Geraldão. Isto se dá por fatores que serão detalhados, todavia, o principal fator que vai de encontro com a realidade de uma organização rígida está relacionado ao nível de discricionariedade das autoridades políticas, ou seja, profissionais convidados para assumir cargo de chefia nessas organizações. Estes, por sua vez irão "determinar" a forma de gestão que deverá adotar a organização. Esta característica de elevada discricionariedade se reflete na realidade do Geraldão, na administração assumida em 2005, onde o gestor numa perspectiva de alcançar inovação nos serviços prestados pela autarquia propôs 
uma nova forma de ação procurando minimizar a burocracia dos procedimentos internos.

Por outro lado, mesmo portando esse direito de escolha, os gestores não podem fugir da formalização dos processos administrativos. A discricionariedade se reporta à forma de organizar - que pode ser diferenciada da gestão anterior mas, existem as reformas administrativas, as alterações de regimentos internos, dentre outros artifícios que os gestores públicos encontram para conseguir dar "a sua cara" ao órgão.

Desta forma, se mostra necessária a formalização dos processos administrativos, através de normatização de tramitação interna de documentos, solicitações, etc. Um fator complicador para essa gestão estudada (2005-2008), se refere a não existência de regimento interno, apesar do órgão ter sido construído há 35 anos, ficando à seu cargo a busca pela padronização desses trâmites, ou seja, a criação de regimento.

Do ponto de vista estrutural, perspectiva analisada neste trabalho, buscou-se em Hall (2004) os elementos dos quais fazem parte da chamada estrutura organizacional e foi destacado (1) as regras, (2) a hierarquia, (3) os mecanismos de controle, (4) os ambientes internos e externos e (5) os membros da organização.

Já citada acima a hierarquia é instituída formalmente através de lei. As regras estão de acordo com as metas e objetivos, no entanto, não estão formalizadas, ou seja, não foram transformadas em lei, dando espaço para emergir ambiente informal nas relações de trabalho.

A hierarquia, conforme organograma apresenta estrutura totalmente verticalizada e os mecanismos de controle se dão através das funções de confiança. Os gerentes deixam os diretores informados e, estes por sua vez, repassam as informações relevantes para a assessoria e diretor-presidente. 0 que chama a atenção é que, pelos documentos analisados, não existe um formato de relatório, um documento formal para o repasse dessas informações. Os acontecimentos são relatados verbalmente e assim, seguem até o ápice da pirâmide hierárquica.

Os ambientes externos e internos do Geraldão se apresentam pela sua peculiaridade política. Diferentemente das organizações privadas inseridas num mercado onde disputam clientes, uma organização pública disputa principalmente recursos orçamentários com outros órgãos que também oferecem serviços à população. No que se refere ao ambiente interno destacamos as relações existentes entre os trabalhadores dos diversos graus da pirâmide, seja num mesmo patamar ou na relação superior-subordinado. Destaca-se uma peculiaridade neste ponto referente às relações, pois, os cargos ocupados por diretores e gerentes são comissionados o que possibilitou a inserção de um 
grupo de trabalho que tinham experiências anteriores e, além disso, uma estreita relação de amizade entre eles.

Aliada a falta de formalização dos processos caracterizados acima, apesar de sua formalização legal e centralização na estrutura hierárquica, existe a predominância de um ambiente informal nas relações de trabalho.

Quanto aos membros da organização, apesar de concordar com Hall (2004) de que fazem parte da estrutura da organização, é possível dizer que eles, os membros, através de suas ações também constroem a estrutura organizacional. Assim, há uma relação dialética entre o papel do agente na organização, ao passo que é transformado, ele também transforma a organização. Esclarecido esse ponto de vista, parte-se para definir a situação referente ao quadro de pessoal da autarquia.

Pode-se dizer que se constituiu uma ação inovadora a implementação de um processo de formação continuada para os trabalhadores, favorecendo o aprimoramento técnico e o desenvolvimento de habilidades referente à nova política de esporte e lazer proposta pela gestão. No entanto, é importante destacar o surgimento de três "tensões" referente ao corpo de profissionais do órgão que se desenvolveu por vários motivos.

A primeira está relacionada com a falta de concurso público para renovação permanente de quadros, criado em 1970, o órgão até então não recebeu profissionais através de concurso público e a cada gestão, os funcionários sofrem as mudanças em virtude do estilo do gestor. Isto criou nos funcionários "da casa" uma espécie de defesa e criação de condutas para preservação de seus espaços na organização. Os costumes e cultura criados por eles dificultavam aos gestores a tomada de qualquer decisão que pudessem prejudicá-los e isto se refletia em funcionários que não cumpriam sua carga horária e mesmo assim, recebiam além do salário, gratificações e horas extras.

A segunda se refere a questão geracional, enquanto o quadro de funcionários efetivos era representado por pessoas mais velhas, alguns em época de se aposentarem, os cargos comissionados estavam sendo ocupados na sua maioria por recém formados, ocasionando um choque geracional, responsável por muitas divergências de conduta. Enquanto um grupo não desejava mais trabalho, aguardando a "hora de sair", o outro estava com toda a expectativa de desenvolver um trabalho diferente e inovador.

A terceira se refere à falta de habilidade da nova gestão em promover eventos/ações na perspectiva de superar esse hiato geracional.

Por fim, fugindo um pouco da questão estrutural e imergindo no conteúdo da política, outro fator que caracterizou esta gestão (2005-2008) foi a capilaridade e aumento da demanda tanto nas atividades esportivas do ginásio - que antes era cobrada à população taxa e hoje é um serviço gratuito - quanto na formação de 
uma rede municipal de esporte e lazer oferecendo serviços de esporte e lazer para as comunidades de baixa renda da cidade.

\section{Análise dos resultados}

Em poucas palavras, o processo de análise realizado neste trabalho envolveu aspectos relacionados como "sujeito implicado" e do "artesanato intelectual", embasados pela análise do conteúdo dos documentos e bibliografias na coleta dos dados. De acordo com a orientação de Bardin (1977) para realização da análise de conteúdo de textos, é necessária a realização da pré-análise, que comporta a organização do material coletado, juntamente com o referencial teórico escolhido pelo pesquisador que formará o corpus da pesquisa citados acima como documentos da organização pesquisada e material relativo ao modelo multidimensional reflexivo; a descrição analítica, onde o material organizado constitui o corpo de documentos que será submetido à análise mais aprofundada e, por fim, a interpretação propriamente dita que poderá ser realizada em relação ao conteúdo manifesto ou latente do material analisado e que será facilitado pela vivência da autora na organização em análise.

As categorias utilizadas para analise da organização terão as seguintes dimensões:

- Estrutural; e

- De agência.

Mesmo sabendo que ambas interferem uma na outra e que estão imbricadas, a estrutura influenciando o comportamento dos agentes e as decisões tomadas pelos agentes influenciando determinado arranjo estrutural, serão abordados separadamente para fins didáticos.

Nas características estruturais são enfatizados os aspectos relacionados por Hall (2004):

- Centralização;

- Formalização; e

- Complexidade. 
Pode-se afirmar que a centralização se refere à distribuição de poder. A centralização pode ser compreendida como o grau em que o poder está centralizado em um sistema social, de forma que o grau máximo existirá se todo o poder for exercido por um único indivíduo (Price 1972). O aspecto centralizador no Geraldão relaciona-se à hierarquia e composição de cargos que são criados por lei. Neste caso, a discricionariedade do gestor não é tão elevada, pois para criar ou excluir determinados cargos é necessário um projeto de lei, votação na Câmara Municipal, dentre outros fatores de convencimento político. No entanto, o que pode acontecer são os desvios de função, ou seja, determinado funcionário lotado num cargo, executando outra atividade. O que não se pôde detectar através da análise de documentos oficiais.

Mesmo com uma estrutura hierarquizada, é possível observar, inclusive em documentos de campo uma abertura para que o planejamento das atividades esportivas sejam elaboradas com a própria turma, e numa esfera superior, as diretorias planejam individualmente suas ações, e através de um processo colegiado, as decisões vão sendo tomadas. Essas ações participativas se deram pelo motivo de se apresentar como desafio do órgão, a elevação do nível de consciência política da população e isto passa pela participação na tomada de decisão. É claro que o peso da decisão de um diretor presidente é relevante, mas antes de "bater o martelo", ele ouve e, no mínimo, reflete sobre a questão antes de determinar uma ação.

Quanto à formalização pode-se afirmar que são "as normas e procedimentos concebidos para lidar com as contingências enfrentadas pela organização", Hall (2004:68), assim como, os meios para assegurar que estas normas e procedimentos sejam seguidos. No caso da organização estudada, a formalização está representada através de uma estrutura de cargos extremamente rígida em sua constituição definidas em decreto-lei.

Apesar disso, o órgão ainda não dispõe de mecanismo legal que regule o seu funcionamento, tal como regimento interno e plano de cargos e carreira. Isto gera uma sobreposição de funções e de outro lado, um hiato em determinados setores onde as ações deveriam ser subsequentes. Outro fator que dificultou a formalização das ações foi a mudança do órgão na reforma administrativa de 2005, pois, passou a assumir novas funções como o planejamento e execução da Política de Esporte e Lazer da cidade do Recife.

Em virtude dessas mudanças, novos procedimentos foram adotados e, além disso, a dificuldade orçamentária tem estimulado novas formas de agir, ou seja, os gestores precisam ser mais criativos para superar as dificuldades da escassez de recursos, ambos os processos levaram os procedimentos formais da organização a constantes mudanças. 
A complexidade de uma organização pode estar associada a sua estrutura hierárquica, geralmente verticalizada, ou a sua relação interssetorial, quando possui uma horizontalidade maior e os setores trabalham dependentes uns dos outros (Hall 2004). Quanto maior o número de ocupações, mais complexa a organização, podendo ainda ser medida pelo grau de instrução dos membros organizacionais (Morin 1998). Pode-se dizer que o Geraldão apresenta os dois aspectos de complexidade num continuum ${ }_{2}$ de um lado a hierarquia altamente estratificada com cinco níveis de poder (presidência, diretorias, gerentes, coordenadores e professores), e de outro, as diretorias que estão no mesmo nível hierárquico e que se relacionam entre si estabelecendo diálogo e integração através de projetos com ações integradas.

Nas características de agência, serão destacados:

- Mecanismos de controle; e

- Características da cultura organizacional representados pelos valores e crenças do órgão.

Em relação ao controle, sua forma é materializada na hierarquia da organização, pois, as informações finais sempre têm que chegar à presidência do ginásio. Cada nível hierárquico possui sua esfera particular, assim como seleciona os dispositivos de controle que mais se adéquam à sua realidade. Não existe uma regularidade ou relatório sistemático que indique falhas e que possam servir de instrumento para correção de rota. As informações geralmente são verbalizadas. Existiu uma tentativa de instituir um sistema de monitoramento, mas for falta de recursos materiais e humanos, não houve uma continuidade, no entanto, quando foi implantado, conseguiu detectar várias falhas como professores sem turma, carga horária não cumprida por professores e agentes comunitários, dentre outras.

A cultura organizacional, caracterizada pelos valores e crenças absorvidos pelos funcionários foi o maior embate da gestão 2005-08 na organização. No órgão criado em 1970, sem a realização de nenhum concurso público para renovação do quadro funcional até então, os funcionários efetivos ficaram refém de mudanças de gestores e a cada quatro anos as regras são alteradas na tentativa de estabelecer novos valores e costumes. Essa vulnerabilidade é decorrente da falta de um regimento interno onde são estabelecidas as "regras do jogo" e, portanto, foram criados alguns códigos de conduta por esses efetivos, a fim de se protegerem dessas oscilações de gestão. Em 2005, com a reforma administrativa mais uma vez esse embate foi travado e em virtude da criação de cargos comissionados (diretores e gerentes principalmente) e contratação direta (professores e agentes comunitários) duas frentes de interesses foram 
estabelecidas, dificultando o trabalho da presidência no sentido de fazer prevalecer uma nova cultura organizacional. Apesar de todas as dificuldades, alguns valores como a participação, o respeito e o bom serviço ao cidadão foram absorvidos pela maioria. Pelo que se pôde observar da organização, é possível levantar algumas características que são contraditórias, como Alves (2003) já havia problematizado: rigidez e flexibilidade, centralização e descentralização e tradição e contemporaneidade e repetição e originalidade.

A organização apresenta os conflitos acima, no entanto, na gestão de 2005-08, observa-se a predominância de certa flexibilidade, descentralização de poder, originalidade nas ações e procedimentos, além da necessidade de um líder que soubesse transitar entre a tradição existente no órgão com a necessidade de estabelecer nova direção para atender à nova missão do Ginásio.

Com essas características evidenciadas e analisando os modelos propostos por Alves (2003) demonstrados acima, pode-se considerar que a estrutura se aproxima ao modelo de organização equiparativo-adaptadora em sua primeira variação, pois, apresenta uma burocracia menos flexível (apesar de ter cargos e hierarquia estabelecidos por lei), possui uma característica de patriarcado renovador, pois consegue o equilíbrio entre as áreas objetiva e subjetiva, tradição e livre arbítrio, além de apresentar uma fraca presença ou eventual ausência da dimensão liderança carismática moderada.

Para maior clareza das características de uma organização equiparativaadaptadora (Quadro 5).

Quadro 5. Característica da organização multidimensional-reflexiva Geraldão. Recife, 2003.

\begin{tabular}{|c|c|c|}
\hline $\begin{array}{l}\text { OMR do tipo } \\
\text { equiparativa- } \\
\text { adaptadora }\end{array}$ & Variação I & Autarquia Geraldão \\
\hline $\begin{array}{l}\text { Burocracia } \\
\text { flexível }\end{array}$ & $\begin{array}{l}\text { Burocracia menos } \\
\text { flexível }\end{array}$ & $\begin{array}{l}\text { Em virtude de sua estrutura ser estabelecida } \\
\text { por lei, mesmo quando necessárias } \\
\text { inovações para atender a missão do órgão. }\end{array}$ \\
\hline $\begin{array}{l}\text { Patriarcado } \\
\text { renovador }\end{array}$ & Patriarcado renovador & $\begin{array}{l}\text { Apesar de todas as dificuldades, o diretor- } \\
\text { presidente estabeleceu minimamente os } \\
\text { critérios necessários para o desenvolvimento } \\
\text { do bom trabalho, criando um novo clima } \\
\text { organizacional. }\end{array}$ \\
\hline $\begin{array}{l}\text { Liderança com } \\
\text { traços mitigados }\end{array}$ & $\begin{array}{l}\text { Fraca presença ou } \\
\text { eventual ausência da } \\
\text { dimensão liderança } \\
\text { carismática moderada }\end{array}$ & $\begin{array}{l}\text { Não foi identificada na gestão analisada uma } \\
\text { presença expressiva da liderança } \\
\text { carismática, neste caso, o diretor-presidente. } \\
\text { As ações eram mais desenvolvidas em } \\
\text { virtude da realização de uma nova política, } \\
\text { do que pelo poder de convencimento do } \\
\text { líder. }\end{array}$ \\
\hline
\end{tabular}




\section{Considerações}

Neste tópico serão retomados os aspectos voltados à introdução do trabalho, aos limites deste estudo e possibilidades para novas pesquisas sobre o tema proposto. Este artigo foi conduzido de forma a possibilitar a discussão sobre a compreensão das características estruturais e dos agentes do Geraldão a partir do modelo de Alves (2003).

Como se pôde observar, o órgão estudado se caracteriza por uma organização de burocracia formal rígida quando falamos de sua estrutura hierárquica, no entanto, ao se tratar de sua organização interna, é possível verificar uma burocracia flexível em virtude de vários fatores, inclusive a escassez de recursos e elevado nível de criatividade para o desenvolvimento dos trabalhos.

Também foi observado um patriarcado renovador com características intermediárias entre o patriarcado reformador que exerce sua vontade diante dos funcionários e o conservador, que tem suas possibilidades diminutas de livre arbítrio. Neste caso, o patriarca se caracteriza como renovador por conseguir adequar tradição e renovação.

Na autarquia há padrões e valores que foram adequados à nova política setorial, gerando uma forma híbrida entre tradição e inovação. A liderança, por sua vez encontra-se com traços mitigados de carisma, em virtude de um líder carismático não derivar sua autoridade de ordens e estatutos como o faz a competência burocrática, nem mesmo de costumes ou promessas, assim como o líder patrimonial, na verdade, a liderança carismática precisa "fazer milagres" ou realizar fatos heroicos para provar a sua missão. Desta forma, como há forte presença de "obediência às regras", não há espaço para desenvolvimento de liderança carismática.

As limitações para a elaboração se apresentaram em dois aspectos. O primeiro, presente na coleta e interpretação dos dados, pois, os documentos oficiais não apresentam abertura para perceber as "entrelinhas" da vida organizacional. Muito do que está registrado formalmente foge à realidade do dia-a-dia da organização. O segundo está na adequação da realidade empírica ao modelo de Alves (2003), que apesar de ser híbrido, não possui a intenção de impor uma estrutura a todas as organizações, em virtude de ter sido idealizado para organizações com fins lucrativos. Desta forma, mesmo chegando a um tipo de classificação segundo o modelo, por definição, ela não refletirá precisamente a realidade da organização em estudo.

\section{Referências}

Alves JAB, Pieranti OP. O Estado e a formulação de uma Política Nacional de Esporte no Brasil. RAE- eletrônica 2007, 6(1):1. 
Alves S. Racionalidade, carisma e tradição nas organizações empresariais contemporâneas. Recife: UFPE, 2003.

Bardin L. Análise de conteúdo. Lisboa: Edições 70, 1977.

Brasil. Constituição Federal. Brasília, 1988. Disponível na internet em: https://www.planalto.gov.br/ccivil_03/Constituicao/Constituiçao.htm [ Acesso em dez. 2008].

Fonseca F. Democracia e participação no Brasil: Descentralização e cidadania face ao capitalismo contemporâneo. Rev. Katálysis 2007, 10(2):245-255.

Gil AC. Como elaborar projetos de pesquisa. 3ạ ed. São Paulo: Atlas, 1991.

Hall R. Organizações: Estrutura, processos e resultados. São Paulo: Pearson Pretice, 2004.

Knight KE. A descriptive model of intra-firm innovation process. Journal of Business 1967, 40:478-496.

Merhy EE. O conhecer militante do sujeito implicado: $O$ desafio em reconhecê-lo como saber válido. Disponível na internet em http://paginas.terra.com.br/saude/merhy [Acesso em mar. 2007].

Mills CW. A imaginação sociológica. Rio de Janeiro: Zahar, 1970.

Morin E. Ciência com consciência. Rio de Janeiro: Bertrand Brasil, 1998.

Pereira AGA. Análise de uma instituição religiosa à luz do modelo multidimensional-reflexivo: A Igreja Presbiteriana em Jardim Atlântico Olinda/PE. Recife. Dissertação de Mestrado - UFPE, 2008.

Price JL. Handbook of organizational measurement. Lexington: Heath, 1972.

Recife (Município). Programa Círculos Populares de Esporte e Lazer (2001-2004). Recife: Secretaria Municipal de Turismo e Esporte, 2002.

Recife (Município). Programa Círculos Populares de Esporte e Lazer (2005-2008). Recife: Secretaria de Educação, Esporte e Lazer / Geraldão, 2005.

Vergara SC. Projetos e relatórios de pesquisa em administração. 4ạ ed. São Paulo: Atlas, 2003.

Weber M. Economia e sociedade. Vol.2. Brasília. UNB, 1999. 